\title{
Devaluation of Pavlovian conditioning in the 10-day-old rat
}

\author{
PHILIPP J. KRAEMER \\ University of Kentucky, Lexington, Kentucky \\ HEATHER HOFFMANN \\ Knox College, Galesburg, Illinois \\ CHRISTOPHER K. RANDALL \\ University of Kentucky, Lexington, Kentucky \\ and \\ NORMAN E. SPEAR \\ State University of New York, Binghamton, New York
}

\begin{abstract}
This experiment established that for the infant rat, 10 days postpartum, a preference conditioned to an olfactory stimulus (conditioned stimulus) could be substantially decreased by subsequently lowering the value of the unconditioned stimulus (heat). This devaluation effect disappeared when a sufficiently long interval elapsed between the devaluation treatment and the test, despite maintained retention of the original conditioned preference over this same interval. This suggests that devaluation in infant rats does not permanently change the animal's original representation of the unconditioned stimulus, but instead may replace it temporarily with a conflicting representation.
\end{abstract}

An issue of central importance to understanding the ontogeny of learning and memory is whether there is an ontogenetic change in the learning process. Do infants and adults go through the same sequence of events that lead to the storage of a new memory and its eventual retrieval?

Although there is not complete agreement as to precisely what constitutes the learning process for the adult, there is some agreement about the general features of this process and the most profitable way to consider it. In discourse about Pavlovian conditioning, it is very rare these days to discuss it as only a matter of associations between stimuli and reflex-like responses. The pertinent level of analysis considers instead associations between the animal's representations of events (e.g., Holland, 1983; Rescorla, 1987; Roscorla \& Holland, 1982).

For instance, theorizing about learning and memory in the adult has emphasized the flexibility of the types of associations acquired by showing that following learning of an A-B association, the animal's response to A can be changed drastically depending upon its subsequent experience with B (see Delamater \& LoLordo, 1991, for a review). An example of special pertinence to the present experiments is unconditioned stimulus (US) devaluation.

The present research was supported by grants from the National Institute of Mental Health (1 RO3 MH42992 to P.J.K. and 1 RO1 MH35219 to N.E.S.). Requests for reprints may be addressed to P. J. Kraemer, Department of Psychology, University of Kentucky, Lexington, KY 40506, or N. E. Spear, Center for Developmental Psychobiology, State University of New York, Binghamton, NY 13901.
Following learning of $\mathrm{A}-\mathrm{B}$, the value of $\mathrm{B}$ may be decreased to the point that subsequent responding to $A$ is reduced to a level that might be expected had $A$ been paired with B after the value of B had been changed (Colwill \& Rescorla, 1986; Delamater \& LoLordo, 1991; Rescorla, 1987). The change in response to $A$ in the absence of any further conditioning of A may be understood by appealing to a change in the animal's representation of $B$.

Devaluation in Pavlovian conditioning may involve pairing an appetitive US with an aversive stimulus, following conditioned stimulus (CS)-US pairings. As an example, Holland and Rescorla (1975) first conditioned rats by pairing a tone with food, which produced a learned increase in activity in the presence of the tone. During devaluation, the food was paired with high-speed rotation. Subsequent presentations of the tone following devaluation elicited less conditioned activity than was shown by control subjects not given the devaluation treatment.

The study of US devaluation may be an especially effective way to analyze potential age-related differences in associative structures that may underlie ontogenetic changes in learning and memory. As an initial consideration of that question, the present experiment was designed to evaluate the effectiveness of US devaluation in 10-dayold rat pups. A number of pilot experiments demonstrated that we could increase the relative preference for lemon odor in rat pups by pairing it with increased ambient temperature. Pups at this age typically prefer banana odor over lemon odor, but the relative preference for lemon can be increased by associating it with an appetitive rein- 
forcer (Alberts, 1984). The pups' inability to thermoregulate efficiently (Leon, 1986) allows ambient heat to serve as an effective US. Our pilot research also indicated that a learned change in the relative preference for lemon odor could be subsequently eliminated by pairing heat with footshock, but this devaluation effect seemed to diminish over the course of a 48-h retention interval (Kraemer, Hoffmann, \& Spear, 1987). The following experiment was intended to replicate these unpublished effects while also demonstrating the associative basis of both the learned odor preference and the subsequent devaluation effect.

\section{METHOD}

\section{Subjects and Apparatus}

Sixty 10-day-old rat pups, derived from six different litters, were randomly assigned to four groups $(n=15)$. The apparatus included a Thermotron MiniMax heating/cooling unit (Model S-1.2). This device consists of an inside stainless steel chamber $(41 \times 28 \times$ $32 \mathrm{~cm}$ ) that can be heated by circulating warm air around the chamber. The floor of the chamber contained a stainless steel grid (21 $\times 26 \mathrm{~cm}$ ), which was attached to a scrambled shock generator (Lafayette Instruments Model 82404-22). Clean cotton cloth was placed underneath the grid floor, which could be scented with $1.5 \mathrm{ml}$ of lemon odor. The test arena consisted of a black wooden box ( 27 $\times 21 \times 9 \mathrm{~cm}$ ) placed on a wire-screen floor that was raised $3 \mathrm{~cm}$ above the surface of the test box. A wooden ridge $(1.5 \times 3 \mathrm{~cm})$ bisected the test box into two equal areas; the ridge was placed between the screen floor and the bottom surface of the box. Cotton strips were placed underneath the screen floor on both sides of the test box.

As many as eight identical boxes could be placed under a ceilingmounted video camera. The camera was attached to a Videomex$\mathrm{V}$ (Columbus Instruments) activity monitor. This device records movement of a user-defined object across a video monitor screen, and it can be used to measure amount and direction of movement. For purposes of this experiment, the system was used to measure the time pups spent on each side of the test box. The test box contained lemon extract $(1.5 \mathrm{ml})$ on one side and banana extract $(1.5 \mathrm{ml})$ on the other side.

\section{Procedure}

Pups were exposed to odor and heat in Phase 1 and heat and footshock in Phase 2 . We have found that rat pups at this age typically show a preference for banana odor over lemon odor, so our tactic was to increase the relative preference for lemon in some groups by associating it with heat (Alberts, 1984). Group P-P received lemon odor and heat paired and heat and shock paired; Group P-UP received lemon and heat paired and heat and shock unpaired; Group UP-P received lemon and heat unpaired and heat and shock paired; and Group UP-UP received lemon and heat unpaired and heat and shock unpaired. In Phase 1 of the experiment, Groups P-P and $P$-UP received three 3 -min exposures to lemon odor in the conditioning chamber at $36^{\circ} \mathrm{C}$. Each odor theat exposure was separated from the next by a 3 -min intertrial interval (ITI) spent in a holding cage at room temperature (approximately $24^{\circ} \mathrm{C}$ ). Groups UP-P and UP-UP received three 3-min exposures to heat in the absence of lemon odor, with exposures separated by 3-min ITIs. Twenty minutes after the last heat exposure, these groups were given three 3-min exposures to lemon odor in the conditioning chamber at room temperature. Phase 2 of the experiment began $2 \mathrm{~h}$ after Phase 1 terminated. All groups received exposure to heat, either paired or unpaired with footshock. Groups P-P and UP-P were given six 20 -sec exposures to the conditioning chamber at $36^{\circ} \mathrm{C}$, with two 2-sec, 1-mA footshocks presented after 8 and $18 \mathrm{sec}$ of heat exposure. Each heat + shock trial was separated from the next by a 1 -min ITI, which was spent in a holding cage maintained at room temperature. Groups P-UP and UP-UP were given six 20 sec exposures to the conditioning chamber at room temperature, with shocks presented after 8 and $18 \mathrm{sec}$. Trials were separated by 1-min ITIs. Twenty minutes after the last shock exposure, these subjects received six 20 -sec exposures to the conditioning chamber at $36^{\circ} \mathrm{C}$, with each exposure separated from the next by a 1 min interval spent in a holding cage at room temperature.

The subjects in each of the four groups were tested either $15 \mathrm{~min}$ or $48 \mathrm{~h}$ after the devaluation phase ( $n=7$ or 8 per group). All testing was conducted at room temperature. The subjects tested at the 15-min retention interval were placed in the holding cage at room temperature until they were tested. The subjects tested at the $48-\mathrm{h}$ retention interval were returned to their home cages with their littermates and dam immediately after the devaluation phase. They were isolated at room temperature for $2 \mathrm{~h}$ before testing. A spatial odor-preference test was used to measure relative preferences for lemon versus banana odors. Each subject was placed on the midline of the test box facing a sidewall and allowed to move freely for $1 \mathrm{~min}$; the subject was then briefly removed and returned to the test box, again placed at the midline facing the sidewall opposite to that of its first placement. The test was continued for $1 \mathrm{~min}$. Total time spent over lemon during the two 1-min test intervals was computed by the Videomex-V activity monitor.

\section{RESULTS}

Mean time over lemon odor for each of the four groups tested at the two retention intervals is presented in Figure 1 . It can be seen that lemon +heat pairings (Group PUP) increased the time pups spent over the lemon relative to pups given heat and lemon unpaired (Group UP-UP). For pups given lemon theat pairings, subsequent heat + shock pairings (Group P-P) reduced the time spent over lemon when testing occured $15 \mathrm{~min}$ after devaluation relative to pups that received heat and shock unpaired (Group P-UP) after initial conditioning. Finally, pups given lemon theat pairings followed by heat and shock either paired (Group P-P) or unpaired (Group P-UP) expressed an increased preference for lemon when tested after a 48-h retention interval relative to comparable groups tested at the 15-min retention interval. Thus, a learned increase in the relative preference for lemon was eliminated by pairing heat with shock, but reappeared when testing was delayed by $48 \mathrm{~h}$.

These conclusions were supported by a $2 \times 2 \times 2$ factorial analysis of varianace, with the factors consisting of conditioning experience (odor and heat paired or unpaired), devaluation experience (heat and footshock paired or unpaired), and retention interval (15 min or $48 \mathrm{~h}$ ). A significant three-way interaction was obtained $[F(1,52)=$ $14.9, p<.01]$. Post hoc comparisons (Newman-Keuls; Keppel, 1991) further revealed that time spent over lemon at the 15-min retention interval was significantly higher in Group P-UP than in each of the other three groups and was significantly lower in Group P-P than in Groups UP-UP and UP-P. Performance also differed as a function of retention interval. The subjects in Groups P-UP and P-P spent significantly more time over lemon at the 48 -h retention interval than did pups given the same 


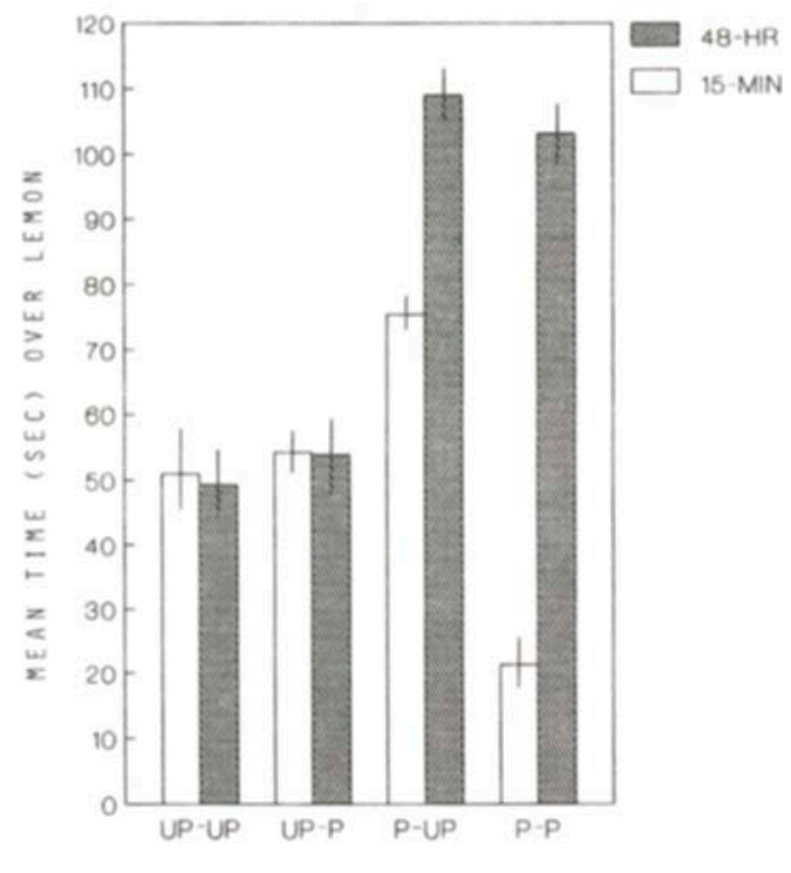

Figure 1. Mean time (in seconds) spent over lemon odor for Groups UP-UP (Unpaired-Unpaired), UP-P (Unpaired-Paired), P-UP (PairedUnpaired), and P-P (Paired-Paired). The first set of letters for each group refers to the relationship between odor and heat during the conditioning phase, and the second set of letters refers to the relationship between heat and footshock during the devaluation phase. Lines on top of the bars indicate standard errors.

training and tested after a $15-\mathrm{min}$ retention interval. In contrast, the subjects in Groups UP-UP and UP-P showed no significant difference in time spent over lemon at the two retention intervals. Finally, the difference in time spent over lemon between Groups P-UP and P-P was significant at the shorter, but not the longer, retention interval.

\section{DISCUSSION}

These results indicate that exposure to paired presentations of lemon odor and heat increases the preference for lemon odor in 10-day-old rats relative to pups exposed to unpaired presentations of lemon and heat. The preference for lemon odor can be subsequently decreased by exposing the same pups to heat paired with footshock; exposure to heat and footshock unpaired does not appear to diminish the learned lemon preference. The devaluation effect, however, seems to dissipate over a 48-h interval, despite good retention of the original odor-heat relation.

One interpretation of this pattern of results assumes that pups not only represented properties of the devalued heat US, but also retained their initial representation of the CS-US relation. When tested soon after conditioning, behavior was consistent with the representation for the devalued US. After the effects of the devaluation episode dissipated, however, pups once again expressed the intact representation of original conditioning.

The dissipation of the devaluation effect could be accounted for in several ways. One possibility is that there was forgetting of the devaluation episode, which then allowed for the expression of the original CS-US association. Another possibility is that inflation occurred. Pups returned to the home nest during the 48-h retention interval could have reacquired associations between heat and other reinforcing events, such as suckling and other aspects of maternal care. Another possibility is that pups given the devaluation treatment formed three-term associations: odor-heat-footshock. The 48-h retention interval could have disrupted the footshock component of the representation, leaving only the odor-heat relation intact. Finally, it is possible that 10 - and 12-day-old rats use different performance rules, and perhaps the intensity of the devaluation treatment must be stronger in 12-day-olds in order for them to express a reduced reaction to the CS. The dissipation of devaluation may thus reflect an agespecific performance effect, rather than a retention deficit. Although the present results cannot distinguish between these alternative interpretations, the important point is that the expression of devaluation in the infant rat appears to be labile.

The increased lemon preference over the 48-h retention interval found in groups given odor theat pairings also deserves comment. It is unlikely that this retention effect reflects a genuine increase in associative strength over time, given that there is no precedent for such an effect in other conditioning procedures at this age. The absence of any change in the unlearned preference for lemon odor over the 48-h retention interval, as indicated by groups exposed to lemon odor and heat unpaired, also suggests that 12-day-old rats do not exhibit any greater inherent preference for lemon odor than do 10-day-olds. One plausible explanation for the retention-interval effect is that the behavioral supports upon which indices of this learned behavior depend change with maturation. For example, a 12-day-old pup is much more proficient than a 10-day-old pup at locomotion. It is possible, therefore, that similar sampling of the two test odors occurred at each age, but the motoric facility of the 12-day-old pup allowed it to move more quickly; thus, at this age, pups could have spent less time over the alternative odor (banana) during each visit than did pups tested at 10 days of age.

There are some other interpretational issues that require comment. One concern is that it is possible that the associations responsible for our results might not have been odor-heat and heat-shock associations as we suggest. Rather, the unpaired procedure could have allowed pups in Group UP-UP to form cool-odor and cool-shock associations (where cool refers to room temperature). Differences in preference for lemon odor between Groups UP-UP and P-UP at the 15-min retention interval could have been due to a devaluation of cool in Group UP-UP, rather than the paired exposure to odor and heat in 
Group P-UP. We believe that this possibility is unlikely for two reasons. First, all subjects had extensive exposure to cool before training and between phases of the experiment, which should have reduced the expression of any odor-cool association. Second, if this account is correct, then lemon preferences should have been lower in Group UP-UP than in Group UP-P; the two groups had the same odor-cool association, but the latter group did not have the cool-shock association.

Another concern is that unpaired exposure to heat and shock necessarily involves exposing pups to room temperature (cool) paired with shock. Given that testing occurred at that temperature (cool), general fear of the cool test context could have produced an enhanced neophobic reaction to the novel banana odor. Perhaps preferences in Groups P-UP and P-P differed as a function of nonassociative fear of banana, rather than as a result of a learned preference for lemon. We consider it unlikely that this explanation is correct. One obvious problem is that lemon preferences at the shorter retention interval were lower in Group P-P than in Group UP-UP. In addition, we are aware of no evidence indicating that contextual fear enhances neophobia in infant rats, although this possibility is sufficiently interesting to warrant empirical consideration. Finally, the extensive nonreinforced exposure to the cool context experienced by all pups would be expected to interfere with their expression of conditioned fear of cool. Thus, we conclude that it is more likely that we obtained a true devaluation of the heat US.

The appearance of US devaluation in the infant rat supports the proposition that there is some similarity between the conditioning processes of the infant and the adult, despite the relatively immature status of the infant's central nervous system (Spear \& Campbell, 1979). As with the adult, conditioning of the infant apparently does not result merely in a direct association between the CS and the animal's response to the US; instead, an association between the CS and the animal's representation of the US seems more likely, because the animal's conditioned reaction to the CS varied in accord with its subsequent experience with the US.

The other notable result from this experiment is that the devaluation effect in infant rats is not necessarily permanent; it can apparently disappear over a retention interval, despite strong retention of the conditioning that preceded the devaluation treatment. This result applies at least for the infant at an age at which retention loss can be quite rapid (Miller, Jagielo, \& Spear, 1989). Whether this effect constitutes a legitimate forgetting phenomenon or an age-related performance effect needs to be examined in future research. If, indeed, forgetting of devaluation occurs in the infant, then perhaps a similar retention effect might emerge in adults. One recommendation for exploring this question in adults is that it could provide another analytical tool with which to extend our understanding of representational processes in animals. Just as overshadowing and latent inhibition have been found to be influenced by retention interval (Kraemer, Lariviere, \& Spear, 1988; Kraemer, Randall, \& Carbary, 1991; Kraemer \& Roberts, 1984), so, too, might devaluation change with delayed testing.

In summary, the picture of the infant rat that emerges at the midpoint of its second postnatal week is of an animal with substantial plasticity and a capacity to acquire memories that are quite malleable, perhaps governed by principles more cognitive in nature than have sometimes been suspected.

\section{REFERENCES}

Alberts, J. R. (1984). Sensory-perceptual development in the Norway rat: $A$ view toward comparative studies. In $R$. Kail \& N. E. Spear (Eds.), Comparative perspectives on the development of memory (pp. 65-101). Hillsdale, NJ: Erlbaum.

Colwill, R. M., Rescorla, R. A. (1986). Associative structures in instrumental learning. In G. Bower (Ed.), The psychology of learning and motivation (Vol. 20, pp. 55-104). New York: Academic Press.

Delamater, A. R. LoLordo, V. M. (1991). Event revaluation procedures and associative structures in Pavlovian conditioning. In L. Dachowski \& C. Flaherty (Eds.), Current topics in animal learning: Brain, emotion, and cognition. Hillsdale, NJ: Erlbaum.

Holland, P. C. (1983). "Occasion-setting" in Pavlovian feature positive discriminations. In M. L. Commons, R. J. Hermstein, and A. R. Wagner (Eds.), Quantitative analyses of behavior: Discrimination processes (pp. 183-206). Cambridge, MA: Ballinger.

Holland, P. C., \& Rescorla, R. A. (1975). The effect of two ways of devaluing the unconditioned stimulus after first- and second-order appetitive conditioning. Journal of Experimental Psychology: Animal Behavior Processes, 1, 355-363.

KEPPEL, G. (1991). Design and analysis: A researcher's handbook. Englewood Cliffs, NJ: Prentice-Hall.

Kraemer, P. J., Hoffmann, H., \& Spear, N. E. (1987, April). The effects of US devaluation in 10-day-old rat pups. Paper presented at the meeting of the Eastern Psychological Association, Arlington, VA.

Kraemer, P. J., Lariviere, N. A., \& Spear, N. E. (1988). Expression of a taste aversion conditioned with an odor-taste compound: Overshadowing is relatively weak in weanlings and decreases over a retention interval in adults. Animal Learning \& Behavior, 16, 164-168.

Kraemer, P. J., Randall, C. K., \& Carbary, T. J. (1991). Release from latent inhibition with delayed testing. Animal Learning \& Behavior, 19, 139-145.

Kraemer, P. J., \& Roberts, W. A. (1984). The influence of flavor preexposure and test interval on conditioned taste aversions in the rat. Learning \& Motivation, 15, 259-278.

LEON, M. (1986). Development of thermoregulation. In E. M. Blass (Ed.), Handbook of behavioral neurobiology (pp. 297-322). New York: Plenum.

Miller, J. S., Jagielo, J. A., \& Spear, N. E. (1989). Age-related differences in short-term retention of the separable elements of a conditioned odor aversion. Journal of Experimental Psychology: Animal Behavior Processes, 15, 194-201.

ResCORLA, R. A. (1987). A Pavlovian analysis of goal-directed behavior. American Psychologist, 42, 119-129.

Rescorla, R. A., \& Holland, P. C. (1982). Behavioral studies of associative learning in animals. Annual Review of Psychology, 33, 265-308.

Spear, N. E., Campbell, B. A. (1979). Ontogeny of learning and memory. Hillsdale, NJ: Erlbaum.

(Manuscript received August 22, 1991; revision accepted for publication March 8, 1992.) 